inflammatory signal, most prominently interleukin-6 (IL-6). Blood levels of CRP may be used as a biomarker for inflammation, cardiovascular disease, dementia, and some epilepsies. The more severe the seizure, the stronger the inflammatory response and the higher the CRP level after an acute seizure. Epileptic seizures provoke a production of cytokines such as IL-6 that may in turn cause an activation of the acute phase reaction and elevation of blood CRP. (Peltola J et al. Indicators of inflammation after recent tonicclonic epileptic seizures correlate with plasma interleukin-6 levels. Seizure 2002 Jan;11(1):44-46).

\title{
CELIAC DISEASE AND INCREASED RISK OF EPILEPSY
}

Researchers at Orebro University Hospital, Orebro, and the Karolinska Institute, Stockholm, Sweden; and the Universities of Naples and Salerno, Italy examined the risk of developing epilepsy in a nationwide population-based sample of $>28,000$ patients with biopsy-verified celiac disease (CD). The absolute risk of future epilepsy in patients with CD was 92/100,000 person-years (excess risk $=27 / 100,000$ person-years), and the risk was independent of age. The hazard ratio (HR) for having at least 2 interactions with health care due to epilepsy was 1.41. In those patients with epilepsy treated with AEDs, the increased risk of epilepsy was 1.43. (Ludvigsson JF, Zingone F, Tomson T, Ekhom A, Ciaccio C. Increased risk of epilepsy in biopsy-verified celiac disease: A populationbased cohort study. Neurology 2012 May 1;78:1401-1407). (Respond: Dr Ludvigsson. E-mail: jonasludvigsson@yahoo.com).

COMMENT. Celiac disease carries a moderately increased risk of epilepsy, and patients with epilepsy are at increased risk of future CD. The increased risk of epilepsy is present both before and after CD diagnosis, indicative of shared risk factors and supportive of an immunological etiology for epilepsy. (Vezzani A et al. The role of inflammation in epilepsy. Nat Rev Neurol 2011;7;31-40).

\section{LONG-TERM EFFECTIVENESS OF ETHOSUXIMIDE, VALPROIC ACID AND LAMOTRIGINE IN ABSENCE EPILEPSY}

Researchers at Seoul National University Bundang and Children's Hospitals, Republic of Korea evaluated the long-term effectiveness and tolerability of ethosuximide (ESX), valproic acid (VPA), and lamotrigine (LTG) as initial monotherapies for patients with childhood absence epilepsy (CAE). CAE was diagnosed according to the criteria of Panayiotopoulos (2005) in a total of 128 patients, female preponderance 1.8:1, and mean age at onset of 6.5 years; 48 were assigned to the ESX group, 59 were treated with VPA and 21 with LTG. The mean follow-up duration was 3.4 years (range, 1-17 years). ESX and VPA starting dose was $10 \mathrm{mg} / \mathrm{kg} /$ day, and $1 \mathrm{mg} / \mathrm{kg} /$ day for LTG. The final maintenance doses were $23 \mathrm{mg} / \mathrm{kg} /$ day for ESX, $26 \mathrm{mg} / \mathrm{kg} /$ day for VPA, and 4.7 $\mathrm{mg} / \mathrm{kg} /$ day for LTG. The seizure-free rate of ESX at 3 months was $84 \%$ and significantly higher than that of VPA $(62 \%)$ and LTG (54\%). At 6 months, the seizure-free rate of ESX (90\%) was significantly higher than that of LTG $(63 \%)$; the seizure-free rates of VPA and LTG groups at 6 months were not significantly different. After 9 months, there was no significant difference in seizure-free rates among the 3 drug groups, nor in rates 